\title{
3D limit equilibrium method for rock slope stability analysis using generalised anisotropic material model
}

\author{
NS Kumar Universiti Sains Malaysia, Malaysia \& Centre of Excellence for Engineering and Technology \\ (CREATE) JKR, Malaysia
}

MAM Ismail Universiti Sains Malaysia, Malaysia

\begin{abstract}
Rock anisotropy is a well-known phenomenon relating to the heterogeneity of rock mass. Nevertheless, its influence in geotechnical design, especially in rock engineering, is often ignored. Slope with certain modes of failure can be evaluated conventionally as well as numerically. For this study, the rock slope assessment was conducted numerically using $2 D$ and $3 D$ limit equilibrium method (LEM) utilising the Slide program by Rocscience. The fundamental roles of the discontinuities present in the study area were evaluated to study their influence on slope stability. Anisotropic material model was incorporated in the LEM analysis to investigate the presence of discontinuities. The measurement of discontinuity orientation in the rock slope by traditional scanline survey is time-consuming and challenging due to accessibility issues. Structure from Motion (SfM) photogrammetry using unmanned aerial vehicle (UAV) allows a quick and cost-effective way to do survey mapping for geotechnical assessment on rock slope compared to terrestrial laser scanner. Dense point cloud is exported to the CloudCompare tool for geological plane extraction. The stability of the rock slope was evaluated using the deterministic 3D and $2 D$ LEM using the geometry of the 3D rock slope system. In this study, the anisotropic material model was utilised to examine the Factor of Safety (FoS) results. Generalised anisotropic material model was used for incorporating the generalised Hoek-Brown criterion (rock mass) and Barton-Bandis criterion (weak joint). The rock mass and shear strength parameter for numerical analysis were determined via destructive and non-destructive tests such as uniaxial compressive strength, Schmidt hardness and joint roughness coefficient estimation using Barton comb. Mean dip/dip direction obtained was used as an input for the value of the anisotropic plane where it causes a weakness in the strength of the rock slope. The results of FoS shows that rock slope without anisotropy model is stable and analysis using anisotropic material model predicts that the slope may fail. 3D slope stability analysis was able to identify the weakest spot easily rather than making an assumption based on the results of 2D slope stability assessment which might represent the whole rock slope. 3D rock slope stability assessment proves to be a very cost-effective method for remedial work whereas in $2 D$ stability assessment, wrong cut-sections may provide inaccurate FoS. This study presents the approach of using anisotropic material model utilising basic rock testing and field observation data to analyse the rock slope stability.
\end{abstract}

Keywords: anisotropy, slope stability, limit equilibrium analysis, generalised Hoek-Brown, Barton-Bandis

\section{Introduction}

The assessment of the stability of natural rock slopes in hilly terrains areas becomes very necessary for implementing safe construction practices. Instability is determined by the occurrence of pre-existing geological features such as joints, bedding planes or rock slopes failures. Failure related to the geological features will normally be in the form of plane sliding, wedge sliding or toppling. Mostly, failure occurs in a rock slope because of one or a combination of these three mechanisms. There are many methods available for evaluating the stability of slope in term of the safety factors, such as limit equilibrium method (LEM), limit analysis method, finite element method and finite difference method. However, there is a need to emphasise the differences in terms of the advantages and parameters of each methods. LEM is a method of essentially dividing a soil/rock mass above the surface of the slip into a finite number of slices where the slices can be 
segmented vertically or horizontally (Cheng et al. 2008; Agam et al. 2016). Numerical simulation methods have gained much attention due to their numerous benefits over LEM. Conventional numerical modelling based on different methods for analysing slope stability in situations where discrete geological structures did not totally control the failure mechanism were not efficient.

It is a general conception that 2D slope stability analysis is too conventional and inadequate in comparison with 3D (Cheng et al. 2005; Leong \& Rahardjo 2012; Nian et al. 2012). Owing to these limitations of apparent instability originating from 2D analysis, comprehensive and practical 3D models were developed. Assessment of $2 \mathrm{D}$ slope stability sometimes leads to over-simplification of the issue and may result in incorrect assessment of the potential failure mechanism. Several researchers have reported that 2D models cannot solve a 3D problem in many situations (Cala 2007; Huang \& Tsai 2000; Nian et al. 2012). Rock mass is largely discontinuous and anisotropic by nature, and this makes the rock a difficult material to be represented mathematically in numerical modelling. Nevertheless, due to the strong anisotropic properties between the normal direction and tangential direction of the bedding joints, the assumption cannot be appropriate for the layered broken rock slope. Amadei (1996) stressed the importance of joint rock mass anisotropy. Different methods have examined anisotropic properties such as elastic modulus and permeability (Gonzaga et al. 2008; Nunes 2002; Snow 1969).

Uniaxial compressive strength (UCS) test, triaxial compressive strength test, point load test, and Schmidt hammer test are the laboratory test conducted to evaluate rock strength. A stone of $54 \mathrm{~mm}$ in diameter is cut from the core and placed under the pair of pistons to be compressed by axial loads. Rock mechanical laboratory testing on core samples is the most accurate method for calculating rock strength. Deere \& Miller (1966) also suggested the use of the Schmidt rebound hammer to measure joint compressive strength. Surface roughness is said to increase the surface's shear strength and this improvement in strength is extremely important in terms of rock excavation stability. Using the Barton comb profilometer, the surface roughness is generated (Kim 2016; Özvan et al. 2014).

Photogrammetry technique has become easier and user-friendly following the recent development of the Structure from Motion (SFM) system and related technologies. Westoby et al. (2012) are providing an introduction to this methodology while Salvini et al. (2017) and Francioni et al. (2018) also recently discussed their applications. SfM is based in multiple overlapping images on a highly redundant bundle adjustment matching features. Although this technique makes it easier and faster to build 3D models, the use of ground control points (GCPs) is still needed for scaling and georeferencing the models (Francioni et al. 2019). Unmanned aerial vehicle (UAV) can be used to capture digital images for photogrammetry processing as long cost solution (Francioni et al. 2019).

This paper aims to conduct the slope stability analysis of a rock slope located in the northern peninsular of Malaysia, that composed of a heterogeneous sedimentary rock system. The 3D analysis will lay a benchmark for Malaysian geotechnical practitioners and the mining industry, thereby serving as the starting point for performing 3D slope stability analysis when considering rock slope. This study consists of collecting data in the field and laboratory testing for the rock strength parameter. Moreover, the analysis will be utilising the parameter determined for rock slope stability study considering the anisotropy condition.

\section{Overview of site and geology}

Construction through karstic limestone is always a challenging task due to the uncertainties. Some part of small 130 hills been blasted to construct a channel to drain the water into Straits of Malaca from Timah Tasoh dam. The blasting activity results in a rock slope to be exposed facing the channel. Some parts of the slope failed due to the presence of weak and heavily jointed rock. The exact coordinate of the study area is at latitude 6.428794 and longitude 100.143884. The study area is located at Kampung Wai, Timah Tasoh, Perlis (Figure 1). Most of the discontinuities are daylighting to the slope face. 


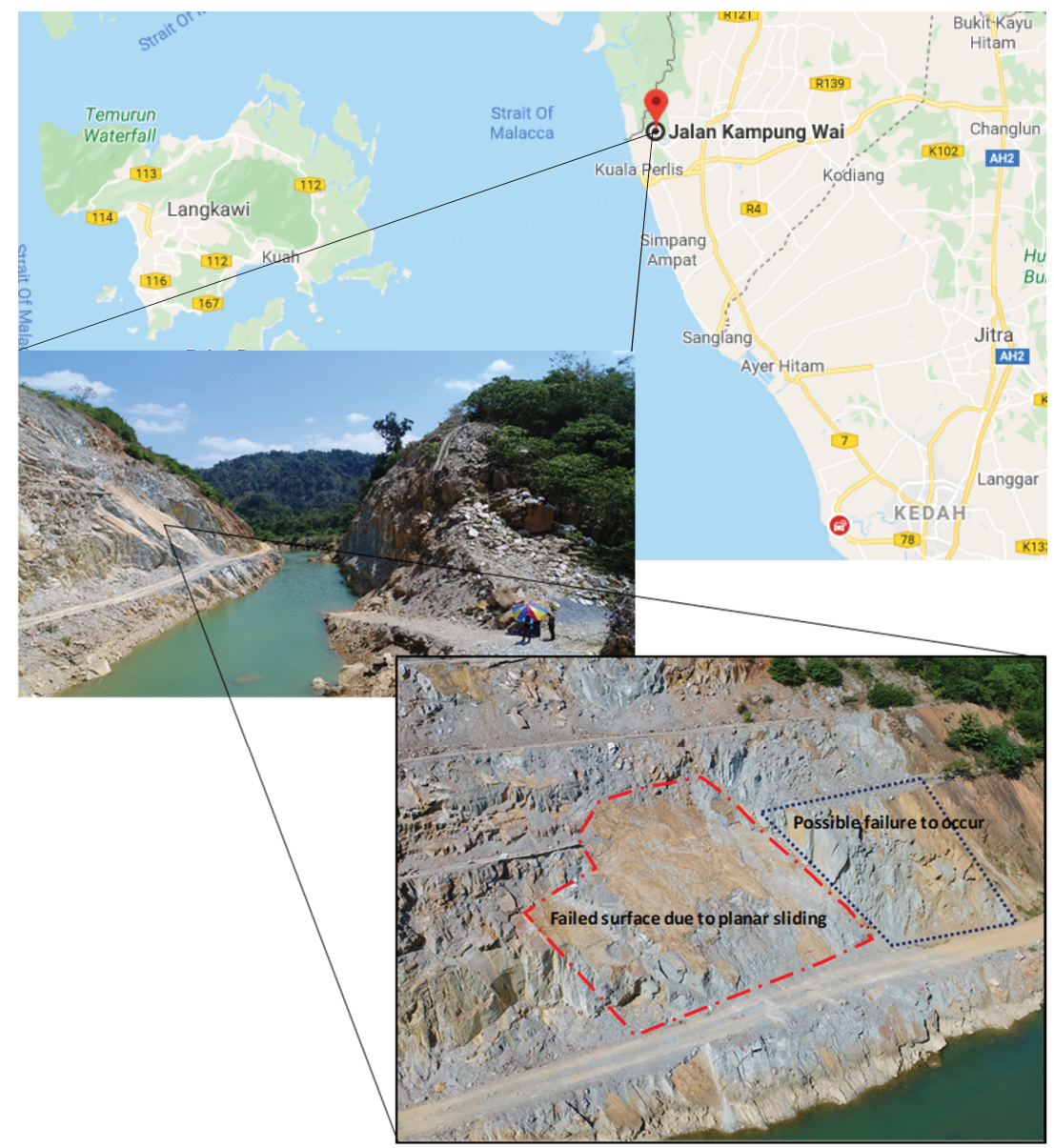

\section{Figure 1 Geological map and site overview}

It is the southernmost limestone range on the mainland of Southeast Asia. Perlis has isolated tower karst hills as well as a long-range of calcareous hills. Perlis is a small state in northern Malaysia. Setul formations are widely distributed in the northwest parts of Peninsular Malaysia and southern Thailand. Setul formations are crystalline, hardly brittle, dark coloured, thick-bedded and crystal clear. Based on Figure 2, the geological settings of the study area are identified as limestone.

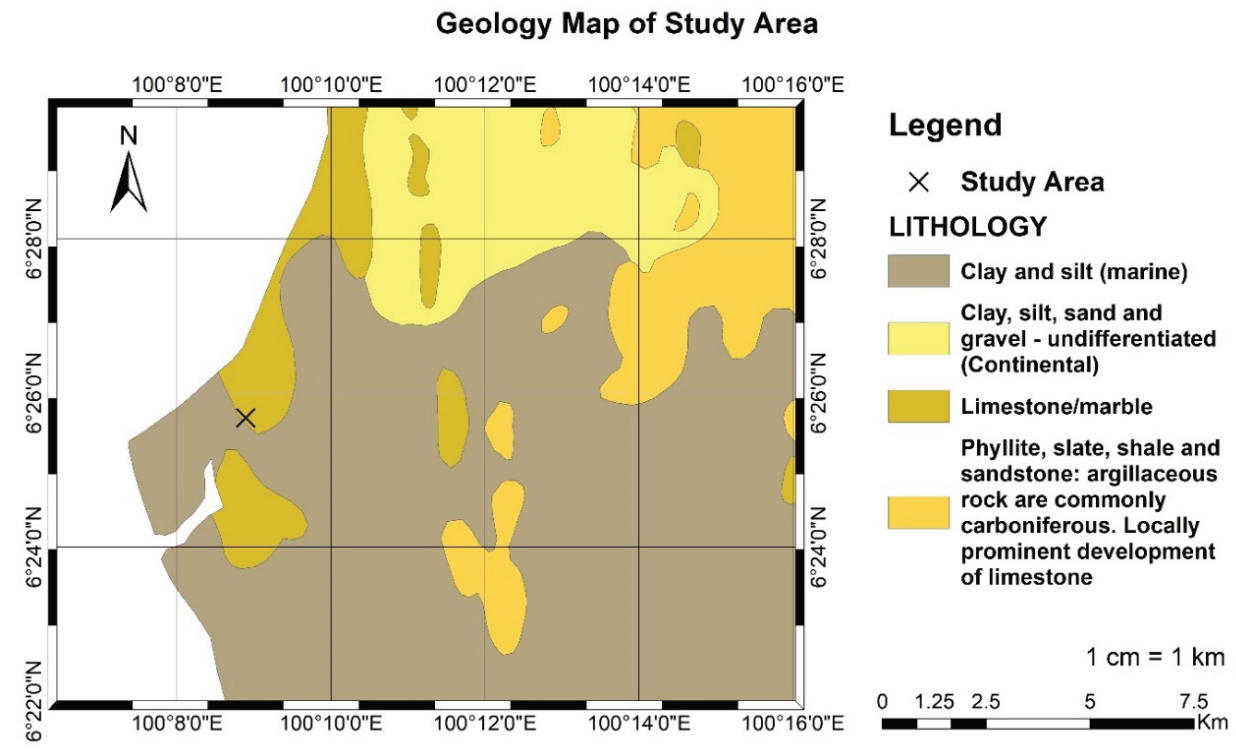

Figure 2 Geological map and site overview 


\section{$3 \quad$ Anisotropic material model}

Anisotropic rock exhibit different properties in various directions. However, rock material exhibits, in most cases, different anomalies in the physical behaviour, which cannot be neglected if a complete solution of any given rock mechanics problem, is to be attained. A well-known behaviour pattern which is of considerable interest in many applications is the rock anisotropy. These anisotropies are often called inherent anisotropic and the rock corresponding to this classified as intact anisotropic rock. (Asadi 2016; Ismael et al. 2014; Kassa \& Steinar 2016). Anisotropic material models use the multi-yield plasticity formulation. It takes one failure criterion for the matrix and virtually number of joints. The shear strength of joints or weak planes could be described by any of the three criteria of Coulomb, Barton-Bandis and hyperbolic. Anisotropic model is a constitutive model that describes the shear strength of an anisotropic rock mass in relation to the change in the angle between the plane of shear, and either the predominant plane of the weakness of the rock fabric or the predominant orientation of major structural weakness. For this study, the generalised anisotropic model will be utilised to simulate the anisotropic condition. The generalised Hoek-Brown model will represent the rock mass strength and the Barton-Bandis criterion will represent the weak joint strength.

The generalised Hoek-Brown criterion for jointed rock masses is introduced by Hoek et al. (2002) in which the shape of the principal stress plot or the Mohr envelope could be adjusted by means of a variable coefficient a as shown in Equation 1:

$$
\sigma_{1}{ }^{\prime}=\sigma_{3}{ }^{\prime}+\sigma_{\mathrm{ci}}\left(\mathrm{m}_{\mathrm{b}} \frac{\sigma^{\prime}{ }^{\prime}}{\sigma_{\mathrm{ci}}}+\mathrm{s}\right)^{\mathrm{a}}
$$

where:

$\mathrm{Mb}=$ a reduced value of the material constant $\mathrm{m}_{\mathrm{i}}$ for the intact rock and is calculated by Equation 2.

$$
\mathrm{m}_{\mathrm{b}}=\mathrm{m}_{\mathrm{i}} \exp \left(\frac{G S I-100}{28-14 \mathrm{D}}\right)
$$

where:

$\mathrm{s}=$ a constant depending upon the characteristics of the rock mass as in Equation 3.

$$
S=\exp \left(\frac{G S I-100}{9-3 D}\right)
$$

Also, parameter a is a constant for the rock mass given by Equation 4:

$$
a=\frac{1}{2}+\frac{1}{6}\left[e^{\left(-\frac{G S I}{15}\right)}-e^{\left(-\frac{20}{3}\right)}\right]
$$

The Barton-Bandis empirical shear strength criterion proposed by Barton was used to describe the shear strength of discontinuities. To use this criterion, the three input parameters of joint roughness coefficient (JRC), joint compressive strength (JCS) and residual friction angle of discontinuity must be determined. Barton and his co-workers (1971-1990) suggested the following empirical criterion for estimating the shear strength of rock joints:

$$
\tau=\sigma_{n} \tan \left[J R C \log 10\left(\frac{J C S}{\sigma_{n}}\right)+\emptyset_{r}\right]
$$

Here $\tau, \sigma_{n}, J C S$ and JRC are shear strength, normal stress, residual friction angle, joint compressive strength and joint roughness coefficient, respectively. For unweathered rock fractures, the residual friction angle $\left(\emptyset_{r}\right)$, is equal to base friction angle $\left(\varnothing_{b}\right)$, which can be obtained from shear tests on smooth unweathered joint surfaces. 


\section{$4 \quad$ Methodology}

\subsection{UAV photogrammetry}

The slope geometry was obtained from the 3D model generated from the UAV photogrammetric method. UAV were used to capture aerial and side images. Later, the images were imported into Agisoft Metashape Professional program for image stitching process using SfM algorithm. UAV data acquisition was carried out using a DJI Phantom 4 Pro quadcopter to capture the aerial and side images of the study area. Planning of missions can be made onsite or at the office before going to the study area (Figure 3a). For this study, the mission was made onsite considering the boundary of an area of interest to capture images to model out the study area. Normal photogrammetry mapping must take into consideration parameters such as flight altitude, percentage of front and side overlapping between images, and ground sampling distance. Waypoints are calculated based on the input parameter and then the UAV mission is usually done in an autonomous mode based on the data transferred to the aircraft. Ground Station Pro from DJI was used to plan the flight parameters to allow the aircraft flies precisely along the pre-designed flight path. GCPs were utilised to georeferencing the model to produce the output with absolute accuracy. Photogrammetry software using SfM technique was able to detect the same features from several images to create the tie point (Figure $3 \mathrm{~b}$ ). Tie points are generated automatically based on feature matching detectors and descriptors such as scale invariant transform. Tie points generated to form three-dimensional coordinates from aerial triangulation process will go through bundle adjustment. 3D point cloud data will be generated after the bundle adjustment process through the photogrammetry software. 3D model of the rock slope was used for numerical modelling in this research work. The object file (.OBJ) format of the 3D model exported into the numerical modelling software to simulate real site condition.
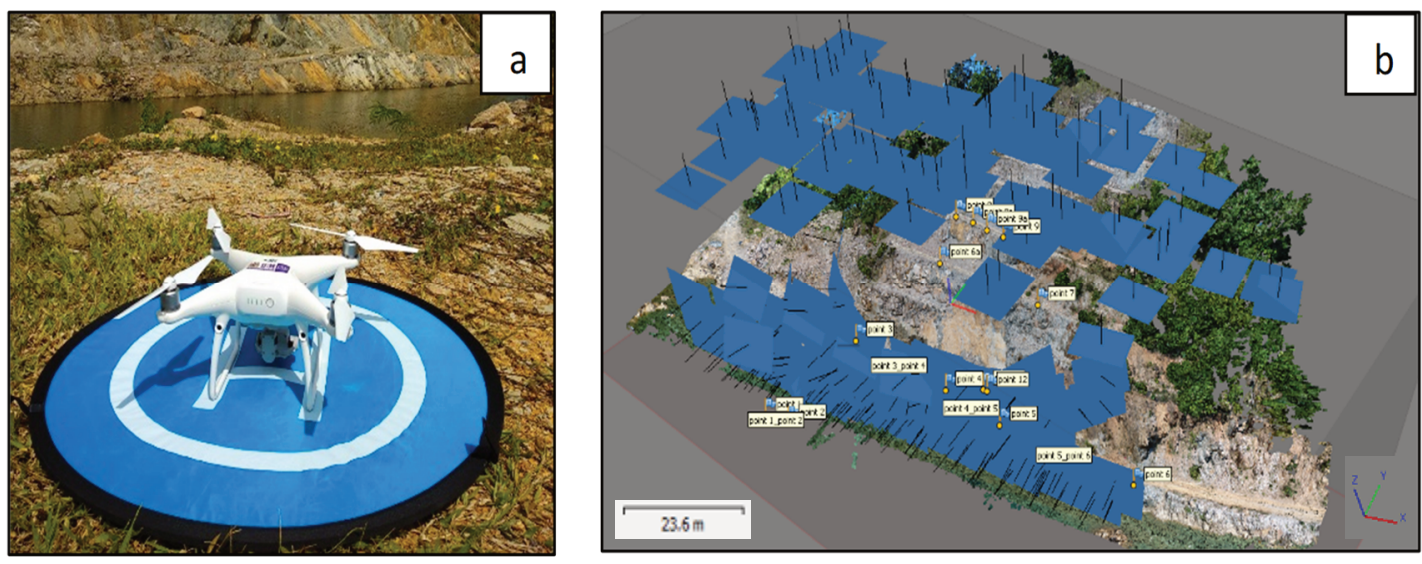

Figure 3 (a) Phantom 4 Pro drone; (b) Agisoft Metashape processing shows the camera position

\subsection{Discontinuity orientation extraction}

The photogrammetry output which is the point cloud data were exported into the open-source tool CloudCompare which utilises FACET plugin (Riquelme et al. 2014). The best features of the FACETS plugin is that it has the capability to discover planar objects but also 3D points with the stereogram tool. This method was able to acquire orientation of discontinuity (dip/dip direction) of the rock slope using an automatic approach by extracting the discontinuity orientation of the rock slope digitally. The 3D point cloud is systematically divided into smaller patches in a fast marching (FM) approach. The divided patches are subsequently regrouped and as a result of which the patches have a similar size. Further, the extracted meshes or facets can be classified into single planes and plane families based on the orientation, i.e. dip/dip direction. The rock slope stability analysis is conducted on the stereogram generated from this process. By selecting the outcrop portion, queries can be raised on the stereogram. Finally, the facets data can also be exported as comma-separated-variable (CSV) ASCII file or shapefiles in order to perform subsequent 
supporting analysis in other software (Dewez et al. 2016). Table 1 shows the input parameters for FACET CloudCompare processing.

Table 1 FACET CloudCompare methods input parameters

\begin{tabular}{lllll}
\hline $\begin{array}{l}\text { Fast marching } \\
\text { algorithm }\end{array}$ & Octree level & Max distance @ 99\% & Min point per facet & Max edge length \\
\cline { 2 - 5 } & $8(0.13 \mathrm{~m})$ & $0.1 \mathrm{~m}$ & 100 & $1 \mathrm{~m}$ \\
\hline
\end{tabular}

\subsection{Methods of acquiring rock strength properties}

\subsubsection{Uniaxial compressive strength}

In this study, a few samples of rock were obtained from different sections of the rock outcrops. A rock sample was cored into the relevant diameter and length ratio 1:2, the diameter of the cored sample was $50 \mathrm{~mm}$ and the length was $100 \mathrm{~mm}$, the coring procedure and standard size were fully complying with ASTM standard D4543-85 (ASTM 2001). The two ends of the specimens were trimmed to make sure the flat-ended on the surface. Polishing and lapping work has been carried out to ensure flat end surfaces not to exceed $0.025 \mathrm{~mm}$ and side of the specimen were straight to within $0.50 \mathrm{~mm}$. Tolerance of the specimen's flatness has to be met according to the ASTM D4543 standard. The uniaxial compression tests were conducted on Shimadzu hydraulic universal testing machine. This machine with $1,000 \mathrm{kN}$ capacity is able to apply the compressive load at a constant strain rate of $0.5 \mathrm{Mpa}$ per second (Figure 4).
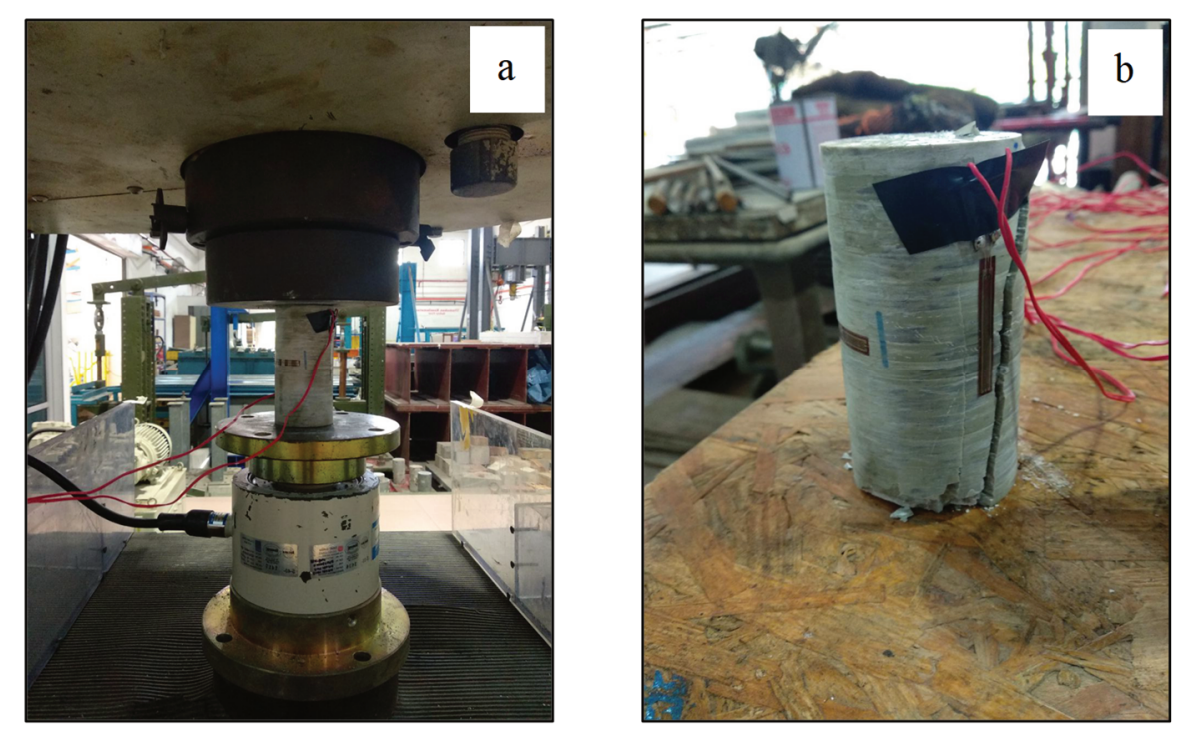

Figure 4 (a) Sample tested for UCS with strain a gauge measurement; (b) Failed sample

\subsubsection{Schmidt hammer}

The JCS were measured using Schmidt rebound hammer in this study (Figure 5a). N-type Schmidt hammer was used to measure the rebound value, $\mathrm{N}$. The test does not involve the destruction of the sample (non-destructive) and it can be repeated on the same sample. The index value obtained is rebound number (N), which is an indicator of surface hardness of the sample. Total of 20 numbers was obtained and the average value was considered as Schmidt number for that section. The $\mathrm{N}$ value was used to estimate the compressive strength of the wall using JCS estimation chart showing the correlation between Schmidt hammer rebound number, hammer orientation, UCS and Rock density by (Deere \& Miller 1966). The determination of surface hardness using Schmidt hammer value obtained following ASTM D5873-00 (ASTM 1981) standard method. 


\subsubsection{Field estimation of joint roughness coefficient}

$\mathrm{JRC}$ is probably the most commonly used approach for quantifying the roughness of a joint profile. A standard method of JRC determination is related to field measurements, which are performed using profilometer (Barton's comb). The attractiveness of the JRC factor is it provides a quantitative measure of discontinuity profile properties. JRC values vary from 0 to 20 were obtained through the comparison of the measured joint surface geometry with the one presented in the Barton's standard profile chart (Barton \& Choubey 1977). It is a simple and easy device to be used for recording the $2 \mathrm{D}$ profile of a short $(30 \mathrm{~cm})$ profile length on a discontinuity surface (Figure $4 \mathrm{~b}$ ). This inexpensive device can be used easily and can be compared to standard JRC profiles or can be traced to obtain a hard copy of the profile. Figure $5(b)$ shows the field application of the device.
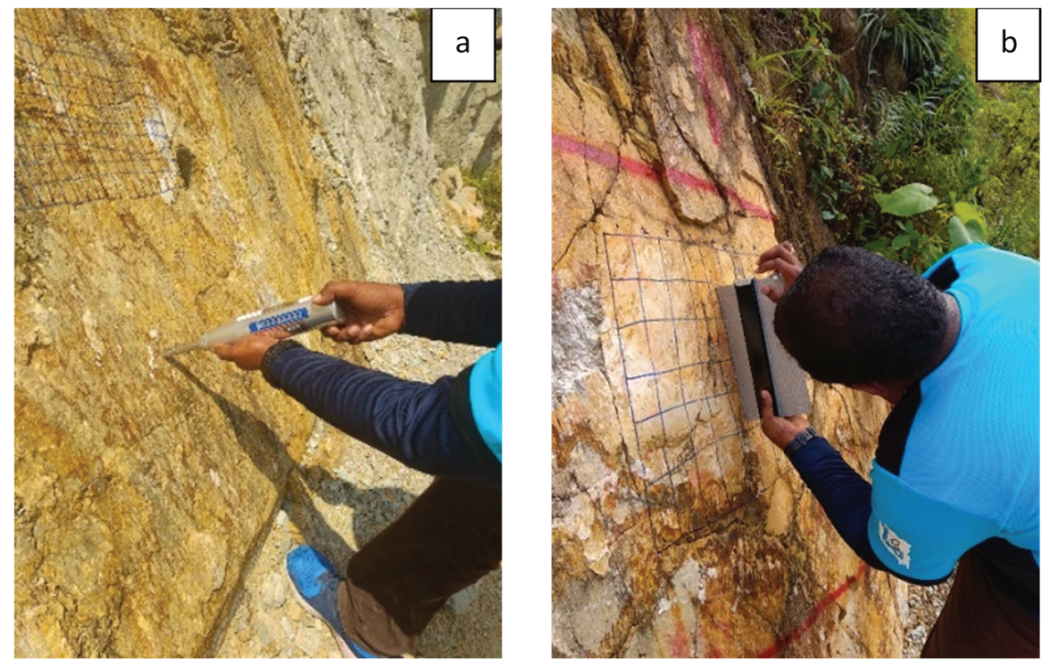

Figure 5 (a) Schmidt hammer reading; (b) Joint roughness measurement using Barton comb

\subsection{D and 3D limit equilibrium modelling}

Discontinuities in the rock mass will be filled up with anisotropic material which does not have the same strength as the intact rock. Their strength is weak and will induce rock slope failure. In this study, the anisotropic plane was assigned to the rock slope to take into consideration of the rock mass strength as well as the weak joint strength which is dipping at an angle. The critical slip surface was searched using cuckoo search method (CS) with surface altering optimisation in the 2D analysis. It is a stochastic method which is more suitable for rock slope, which consists of irregular and heterogeneous anisotropic plane and material where non-circular slip surface occur. CS can locate the absolute global minimum failure surface more effectively and efficiently (about three times faster) than the simulated annealing method (Wu 2012) (Mohamad et al. 2014). The non-circular slip surface type was selected due to the anisotropic plane (discontinuity). The slope stability assessment was performed using the limit equilibrium method using GLE/Morgenstern-Price criterion since it involved horizontal and vertical force equilibrium as well as moment equilibrium. The generalised anisotropic strength model permits to define anisotropic strength characteristic for material using any combination of failure criteria applied across different orientations. The generalised anisotropic strength model allows us to define anisotropic strength properties for material using any combination of failure criteria applied over different orientations. Dip and dip direction were used to define the anisotropy. The composite materials of the rock slope must be defined with its strength characteristic. The $A$ and $B$ parameters define the angular range of the anisotropy. For this analysis, parameter $A$ is equal to 5 (commonly adopted in geological model to be used for slip surfaces in LEM analysis software) and $B$ is $10^{\circ}$ (used for the discontinuous joints mainly for back analyses and collapsed slopes) was used to represent the angular variation (Bar \& Weekes 2017). Different failure criteria can be selected to define the strength of the composite materials in the generalised anisotropic. For this study, rock mass strength has been expressed through the Hoek-Brown failure criterion. Since rock mass has discontinuities, a generalised anisotropic 
model was used to define the orientations of the anisotropic plane in the rock slope. Bedding/weak joint was defined by Barton-Bandis failure criterion.

\section{$5 \quad$ Results and discussion}

\subsection{Laboratory and field observation data}

Based on the laboratory test conducted using the cored sample, the summary of the results tabulated below (Table 2). The preparation of a sample for this destructive testing needs more caution. Due to the moderately weathered sedimentary rock, the sample tends to break during coring. All the results were compared to the findings from other researcher's work on limestone.

Table 2 Laboratory results using cored sample

\begin{tabular}{|c|c|c|c|c|c|c|c|}
\hline $\begin{array}{l}\text { Sample } \\
\text { number }\end{array}$ & $\begin{array}{l}\text { Dry density } \\
\left(\mathrm{g} / \mathrm{cm}^{3}\right)\end{array}$ & $\begin{array}{l}\text { Uniaxial compressive } \\
\text { strength (Mpa) }\end{array}$ & $\begin{array}{l}\text { Min } \\
\text { values }\end{array}$ & $\begin{array}{l}\text { Max } \\
\text { value }\end{array}$ & Median & Mean & $\begin{array}{l}\text { Standard } \\
\text { deviation }\end{array}$ \\
\hline 1 & 2.724 & 50 & \multirow{8}{*}{50.7} & \multirow{8}{*}{101.4} & \multirow{8}{*}{67.54} & \multirow{8}{*}{73.35} & \multirow{8}{*}{18.82} \\
\hline 2 & 2.757 & 69.5 & & & & & \\
\hline 3 & 2.746 & 101.4 & & & & & \\
\hline 4 & 2.738 & 80.9 & & & & & \\
\hline 5 & 2.723 & 62.84 & & & & & \\
\hline 6 & 2.754 & 56.79 & & & & & \\
\hline 7 & 2.735 & 65.58 & & & & & \\
\hline 8 & 2.746 & 99.08 & & & & & \\
\hline
\end{tabular}

The Schmidt hammer in situ strength characteristics of the rocks were determined by performing 60 Schmidt hammer tests at different parts along the rock slope outcrops. The in situ results were plotted on the correlated chart to obtain the JCS value (Table 3).

Table 3 Results of Schmidt hammer for joint compressive strength estimation

\begin{tabular}{llll}
\hline Section & $\begin{array}{l}\text { Schmidt } \\
\text { hammer (N) }\end{array}$ & Average & $\begin{array}{l}\text { Joint compressive } \\
\text { strength (MPa) }\end{array}$ \\
\hline 1 & 35.2 & & \\
2 & 28.0 & 32.3 & 52 \\
3 & 32.1 & & \\
4 & 33.9 & & \\
\hline
\end{tabular}

JRC results from the Barton comb summarised based on the data collected at three sections section of the rock slope outcrops. A total of 30 data values were collected and summarised according to each section of the rock slope outcrops (Figure 6). 

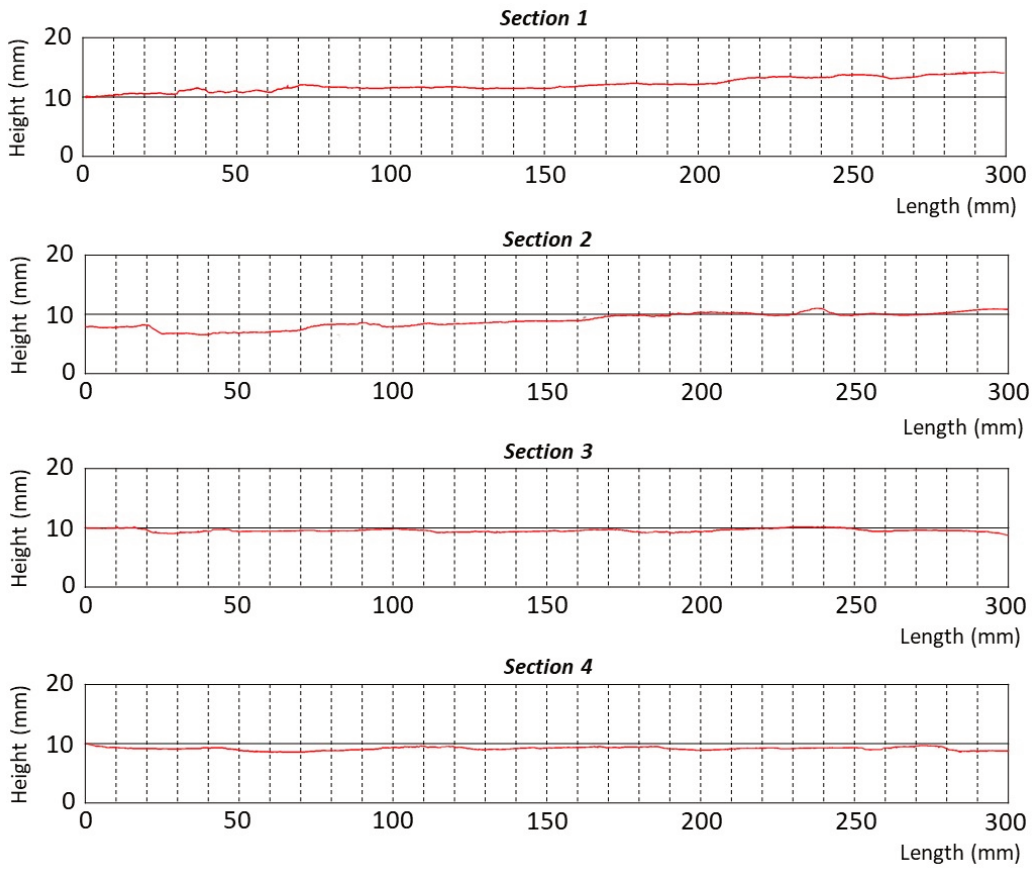

\section{Figure 6 Manual measurement (Barton's comb)}

In CloudCompare, the discontinuities present in the rock mass was extracted using the FACET plugin. Of the 59 million points, 31 million points corresponded to the outcrop. Based on the dip/dip directions, a total of 3,852 facets were produced, and grouped after the FM approach in the plane segmentation process was carried out. Two major discontinuity sets can be observed from Figure 6a, namely Set 1 (green) and Set 2 (blue). While the mean dip/dip direction for Set 1 was $046^{\circ} / 172^{\circ}$, it was $043^{\circ} / 189^{\circ}$ for Set 2 , as shown in Figure $6 \mathrm{~b}$. For the entire rock slope, the mean dip/dip direction is $035^{\circ} / 186^{\circ}$ as depicted in Figure $6 \mathrm{c}$. The stereograms shown in Figure 7 exported from CloudCompare, were plotted in dip vector mode. The values extracted from this output have been verified using a scanline survey. Manual measurement of orientations using scanline survey method was used to verify the accuracy of the extraction of geological planes by FACET plugin in CloudCompare. The dip/dip direction of the same location was extracted from the software to compare with that obtained manually. The data is tabulated in Table 4 . There is a difference of $10^{\circ}$ of dip angle between the data extracted digitally from the CloudCompare tools and the manual measurement.

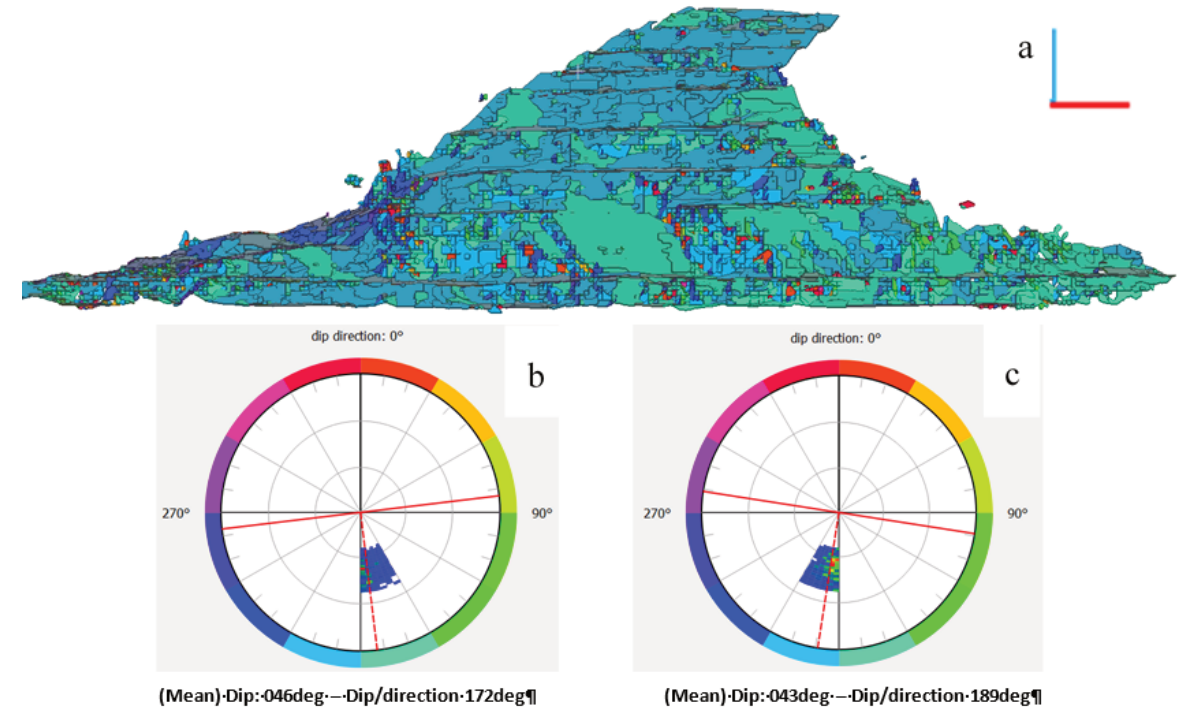

Figure 7 (a) Facets extracted from 3D dense cloud and Stereogram; (b) Green set; (c) Blue set 
Table 4 Comparison of dip/dip direction obtained manually and from software

\begin{tabular}{|c|c|c|c|c|}
\hline \multirow{2}{*}{$\begin{array}{l}\text { Chainage } \\
\text { number }\end{array}$} & \multicolumn{2}{|c|}{ Scanline survey } & \multicolumn{2}{|c|}{ Extraction from software } \\
\hline & Dip angle $\left({ }^{\circ}\right)$ & Dip direction $\left({ }^{\circ}\right)$ & Dip angle $\left({ }^{\circ}\right)$ & Dip direction $\left({ }^{\circ}\right)$ \\
\hline \multirow[t]{4}{*}{$2890-2900$} & 70 & 230 & 68 & 223 \\
\hline & 80 & 100 & 82 & 95 \\
\hline & 40 & 160 & 44 & 164 \\
\hline & 80 & 80 & 71 & 89 \\
\hline \multirow[t]{3}{*}{$2880-2890$} & 85 & 260 & 85 & 253 \\
\hline & 50 & 160 & 46 & 162 \\
\hline & 90 & 80 & 82 & 85 \\
\hline \multirow[t]{3}{*}{$2870-2880$} & 70 & 80 & 79 & 91 \\
\hline & 40 & 190 & 39 & 179 \\
\hline & 50 & 170 & 44 & 180 \\
\hline \multirow[t]{3}{*}{$2860-2870$} & 50 & 170 & 45 & 175 \\
\hline & 90 & 250 & 85 & 243 \\
\hline & 60 & 180 & 61 & 183 \\
\hline \multirow[t]{4}{*}{$2850-2860$} & 50 & 170 & 52 & 175 \\
\hline & 75 & 40 & 83 & 45 \\
\hline & 65 & 222 & 66 & 232 \\
\hline & 80 & 70 & 82 & 85 \\
\hline \multirow[t]{4}{*}{ 2840-2850 } & 40 & 230 & 36 & 220 \\
\hline & 30 & 210 & 34 & 213 \\
\hline & 60 & 80 & 49 & 77 \\
\hline & 40 & 220 & 35 & 205 \\
\hline \multirow[t]{2}{*}{ 2830-2840 } & 50 & 70 & 49 & 77 \\
\hline & 40 & 180 & 43 & 185 \\
\hline \multirow[t]{2}{*}{$2820-2830$} & 45 & 150 & 44 & 154 \\
\hline & 30 & 170 & 35 & 167 \\
\hline \multirow[t]{2}{*}{$2810-2820$} & 50 & 160 & 48 & 164 \\
\hline & 40 & 160 & 43 & 168 \\
\hline \multirow[t]{4}{*}{$2800-2810$} & 80 & 30 & 77 & 39 \\
\hline & 60 & 150 & 54 & 159 \\
\hline & 30 & 180 & 43 & 190 \\
\hline & 70 & 240 & 66 & 232 \\
\hline
\end{tabular}


In situ observation and basic laboratory tests were conducted to obtain the rock input parameters. The phir angle was obtained from the basic tilt test experiment. Table 5 shows the summary of input parameters used for numerical modelling of the rock slope.

Table 5 Input parameter of rock material for anisotropic slope stability analysis

\begin{tabular}{|c|c|c|c|}
\hline Material & Parameters & & Comments \\
\hline \multirow{5}{*}{$\begin{array}{l}\text { Rock mass } \\
\text { (Generalised } \\
\text { Hoek-Brown) }\end{array}$} & Unit weight & $27 \mathrm{kN} / \mathrm{m}^{2}$ & \\
\hline & $\begin{array}{l}\text { Uniaxial compressive } \\
\text { strength }\end{array}$ & $73.34 \mathrm{MPa}$ & \\
\hline & $\begin{array}{l}\text { Geological strength } \\
\text { index (GSI) }\end{array}$ & 59 & $\begin{array}{l}\text { Calculated based on (Bieniawski 1989) } \\
1.5 \mathrm{JCond}_{89}+\mathrm{RQD} / 2=(1.5) 16+70 / 2=59\end{array}$ \\
\hline & Mi value & 10 & Spiritic Limestones \\
\hline & Disturbance factor (D) & 0.8 & Poor to Good Blasting \\
\hline \multirow{3}{*}{$\begin{array}{l}\text { Weak joint } \\
\text { (Barton-Bandis) }\end{array}$} & $\begin{array}{l}\text { Joint compressive } \\
\text { strength }\end{array}$ & $52 \mathrm{MPa}$ & \\
\hline & $\begin{array}{l}\text { Joing roughness } \\
\text { coefficient }\end{array}$ & 4 & $\begin{array}{l}\text { JCS and JRC from correlated N value from } \\
\text { (Barton \& Choubey 1977) }\end{array}$ \\
\hline & Phir & 33 degrees & \\
\hline
\end{tabular}

\subsection{D and 3D slope stability analysis with and without anisotropy}

Two cases of rock slope stability analysis were carried out: without anisotropic plane, which is a control set, and with anisotropic plane. The rock slope stability for both cases was analysed by a deterministic method in 3D. Besides, cut-sections were extracted from 3D rock geometry respectively and analysed by deterministic method in 2D. All the rock input parameters for both cases are the same except for the existence of anisotropic plane. The mean dip/dip direction obtained was used as an input for the value of the anisotropic plane where it causes a weakness in the strength of the rock slope. Figures $8 \mathrm{a}$ and $8 \mathrm{~b}$ depicts the FoS of the $3 \mathrm{D}$ analysis with rock mass strength only. Figure 9 shows the surface failure of $2 \mathrm{D}$ rock geometry analysed without anisotropic plane considering rock mass strength only. The least FoS of the entire rock slope is 5.446 (3D) and 4.716 (2D) respectively. This value indicates that the rock slope will be very stable if anisotropic plane is not considered. Figure 10a, 10b and 11 illustrates the FoS of the 3D and 2D rock geometry analysed with the anisotropic plane. The input dip/dip directions are $043^{\circ} / 189$ and ${ }^{\circ} 046^{\circ} / 172^{\circ}$. The least deterministic FoS of the entire rock slope obtained is 1.089 and 0.771 respectively. This value indicates that the rock slope is less stable and tends to fail at any time. 

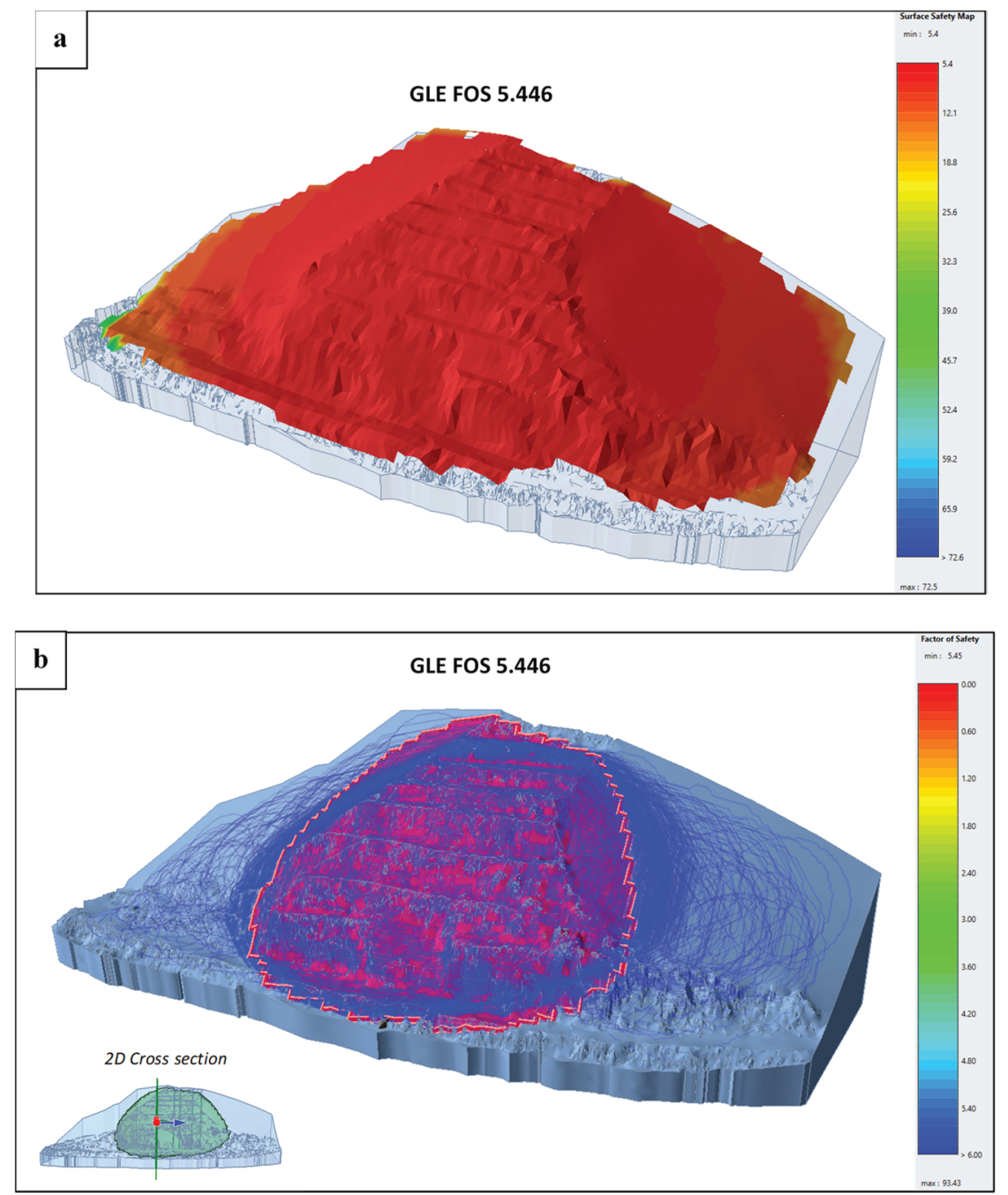

Figure 8 (a) Surface safety map; (b) Factor of Safety of rock slope without anisotropic plane in 3D

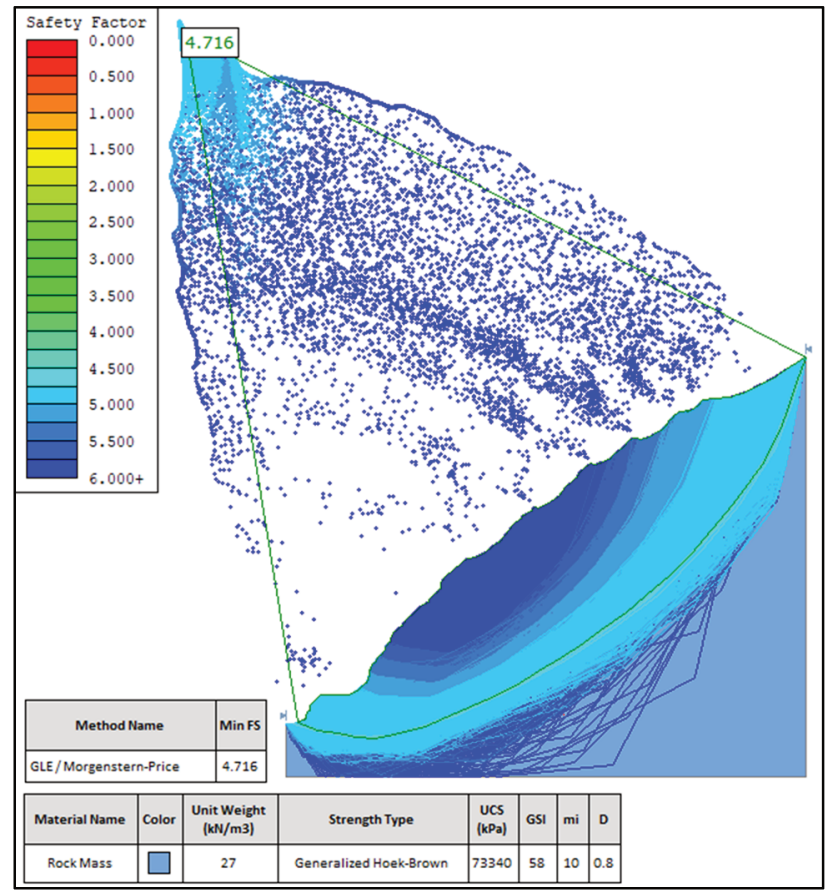

Figure 9 Factor of Safety of rock slope without anisotropic plane in 2D 

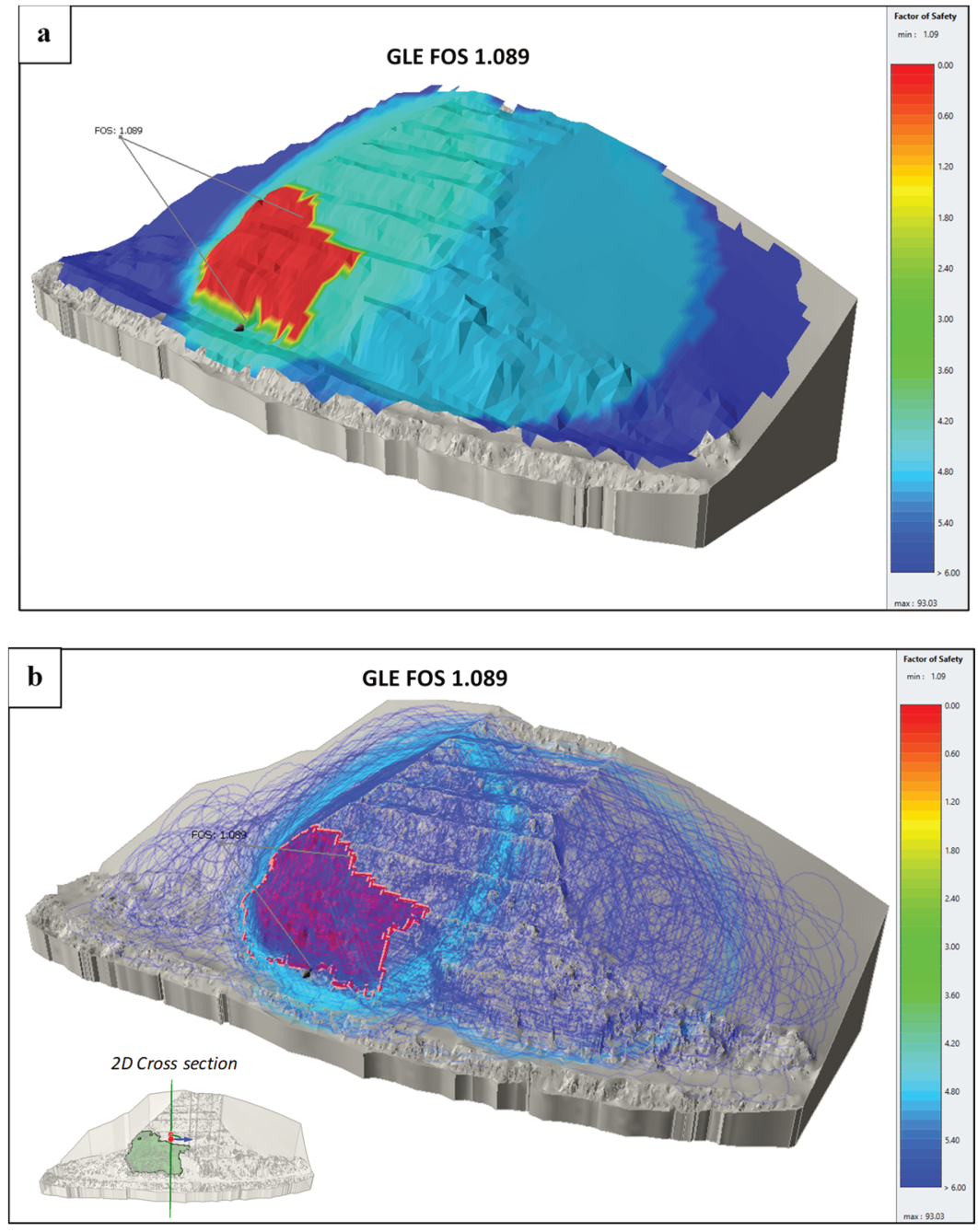

Figure 10 (a) Safety map of surface and (b) Factor of Safety of rock slope with anisotropic plane in 3D

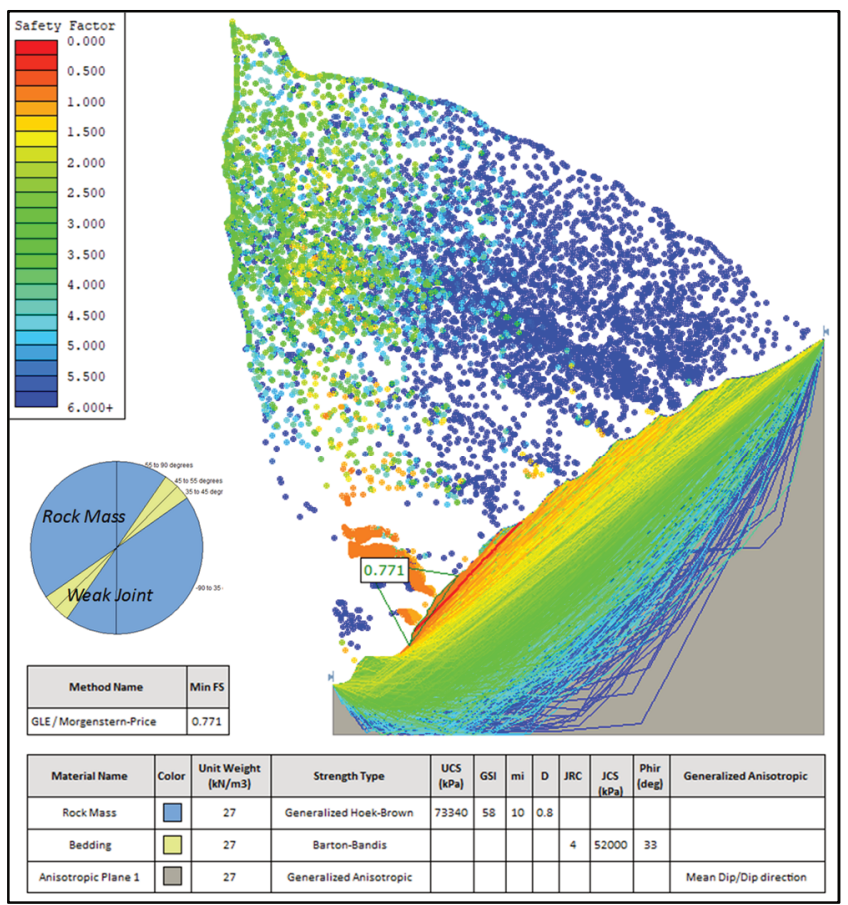

Figure 11 Factor of Safety of rock slope with anisotropic plane in 2D 
The FoS of rock slope with and without the anisotropic plane in 3D and 2D analysis is tabulated in Table 6. Besides, the 3D deterministic analysis gives higher FoS than that of 2D deterministic analysis. The difference is because the 3D failure surface does not cross weak rock surface only, but also strong ones, neglecting the over-conservative simplification assumed within the 2D sections. Furthermore, the lower FoS of rock slope with anisotropic plane indicates that the orientations of the joints in the rock slope play an important role in determining the strength of the rock mass. It will contribute to the weakness of the rock mass. Furthermore, the lower FoS of rock slope with anisotropic plane indicates that the orientations of the joints in the rock slope play an important role in determining the strength of the rock mass. The angle of orientation is significant therefore it is a parameter that cannot be ignored when dealing with rock slope stability analysis. The value of orientation is significant and therefore it is a parameter that cannot be ignored when dealing with rock slope stability analysis. The rock slope orientation is also daylighting towards the valley which is another factor that shows failure may occur. Based on the field observation, some port of the slope has failed, this satisfies the results of with anisotropic plane. Planar sliding was observed as the most common failure mode along the rock slope.

Table 6 Results of 2D and 3D slope stability analysis

\begin{tabular}{lll}
\hline Anisotropic plane & $\begin{array}{l}\text { Least deterministic Factor of } \\
\text { Safety (FoS) in 3D analysis }\end{array}$ & $\begin{array}{l}\text { FoS in 2D analysis (global } \\
\text { minimum surface) }\end{array}$ \\
\hline Without & 5.446 & 4.716 \\
With & 1.089 & 0.771 \\
\hline
\end{tabular}

\section{Conclusion}

SfM is one of the costs and time-effective methods in the aerial mapping of rock slopes. The 3D textured geometric model of the rock slope produced was used for rock slope stability analysis together with the orientations extracted act as the variables. The geological planes extracted from the high accuracy dense point cloud using FACET plugin in CloudCompare is considered reliable and accurate. Two major discontinuity sets and random discontinuities were identified during the extraction of the facets plane. Considering that the anisotropic plane is important since the rock slope is heterogeneous, having various discontinuity patterns, unpredictable and anisotropic, the geotechnical parameters of rock and discontinuities were considered effective factors in the stability of rock slopes. Understanding the geology remains a tough challenge as despite being detailed, all models may be wrong if the geology is not understood and appropriately interpreted. Strength of anisotropy must be considered in the rock slope stability assessment to portray the effects of discontinuities present in the rock mass. The utilisation of 3D rock slope stability assessment was able to reduce the cost of slope remedial measures based on the failure spot. Application of anisotropy model was able to demonstrate the weakness plane in the rock mass and the stability analysis while neglecting the anisotropic condition may result in a wrong interpretation of the FoS.

\section{Acknowledgement}

The authors express their gratitude to Universiti Sains Malaysia fellowship program for providing financial assistance in the form of scholarship. This work was also supported by the Universiti Sains Malaysia bridging grant. The authors express their sincere appreciation to the lecturers, technicians and peers of the School of Civil Engineering, Universiti Sains Malaysia, who have contributed towards this research.

\section{References}

Agam, MW, Hashim, MHM, Murad, MI \& Zabidi, H 2016, 'Slope sensitivity analysis using Spencer's method in comparison with general limit equilibrium method', Procedia Chemistry, vol. 19, pp. 651-658, http://dx.doi.org/10.1016/j.proche.2016.03.066

Amadei, B 1996, 'Importance of anisotropy when estimating and measuring in situ stresses in rock', International Journal of Rock Mechanics and Mining Sciences and Geomechanics Abstracts, vol. 33, issue 3, pp, 293-325. 
Asadi, M 2016, 'Optimized Mamdani fuzzy models for predicting the strength of intact rocks and anisotropic rock masses', Journal of Rock Mechanics and Geotechnical Engineering, vol. 8, issue 2, pp. 218-224, http://dx.doi.org/10.1016/j.jrmge.2015.11.005

ASTM D4543 2001, Standard Practices for Preparing Rock Core Specimens and Determining Dimensional and Shape Tolerances, ASTM International, https://doi.org/10.1520/D5079-08

ASTM D5873 1981, Determination of Rock Hardness by Rebound Hammer Method 1, ASTM International.

Bar, N \& Weekes, G 2017, 'Directional shear strength models in 2D and 3D limit equilibrium analyses to assess the stability of anisotropic rock slopes in the Pilbara Region of Western Australia', Journal and News of the Australian Geomechanics Society, vol. 52, issue 4, pp. 91-104.

Barton, N \& Choubey, V 1977, 'The Shear Strength of Rock Joints in Theory and Practice', Rock Mechanics Felsmechanik Mécanique Des Roches, vol. 10, pp. 1-54, https://doi.org/10.1007/BF01261801

Bieniawski, ZT 1989, Engineering Rock Mass Classifications: A Complete Manual for Engineers and Geologists in Mining, Civil, and Petroleum Engineering, Wiley, Hoboken.

Cala, M 2007, 'Convex and concave slope stability analyses with numerical methods', Archives of Mining Sciences, vol. 52, issue 1, pp, 75-89.

Cheng, YM, Lansivaara, T \& Siu, J 2008, 'Impact of Convergence on Slope Stability Analysis and Design', Computers and Geotechnics, vol. 35, issue 1, pp, 105-113.

Cheng, YM, Liu, HT, Wei, WB \& Au, SK 2005, 'Location of Critical Three-Dimensional Non-Spherical Failure Surface by NURBS Functions and Ellipsoid with Applications to Highway Slopes', Computers and Geotechnics, vol. 32, issue 6, pp. 387-399.

Deere, DU \& Miller, RP 1966, Engineering classification and index properties for intact rock, technical report, Air Force Weapons Laboratory

Dewez, TJB, Girardeau-Montaut, D, Allanic, C \& Rohmer, J 2016, 'Facets : A Cloudcompare plugin to extract geological planes from unstructured 3D point clouds', International Archives of the Photogrammetry, Remote Sensing and Spatial Information Sciences, pp. 799-804, https://doi.org/10.5194/isprsarchives-XLI-B5-799-2016

Francioni, M, Simone, M, Stead, D, Sciarra, N, Mataloni, G \& Calamita, F 2019, 'A new fast and low-cost photogrammetry method for the engineering characterization of rock slopes', Remote Sensing, vol. 11, issue 11, pp. 1-24.

Francioni, M, Salvini, R, Stead, D \& Coggan, J 2018, 'Improvements in the integration of remote sensing and rock slope modelling', Natural Hazards, vol. 90, issue 2, pp. 975-1004.

Gonzaga, GG, Leite, MH \& Corthésy, R 2008, 'Determination of anisotropic deformability parameters from a single standard rock specimen', International Journal of Rock Mechanics and Mining Sciences, vol. 45, issue 8, pp, 1420-1438.

Hoek, E, Carranza, C \& Corkum, B 2002, 'Hoek-Brown failure criterion - 2002 edition', Proceedings of the 5th North American Rock Mechanics Symposium and the 17th Tunnelling Association of Canada Conferenec, vol. 1, pp. 267-273.

Huang, CC \& Tsai, CC 2000, 'New Method for 3D and Asymmetrical Slope Stability Analysis', Journal of Geotechnical and Geoenvironmental Engineering, vol. 126, issue 10, pp. 917-927.

Ismael, MA, Imam, HF \& El-Shayeb, Y 2014, 'A Simplified Approach to Directly Consider Intact Rock Anisotropy, in Hoek-Brown Failure Criterion', Journal of Rock Mechanics and Geotechnical Engineering, vol. 6, issue 5, pp. 486-92, http://dx.doi.org/10.1016/j.jrmge.2014.06.003

Kassa, HM \& Steinar, N 2016, 'Numerical models on anisotropy of rocks', Proceedings of the 17th Nordic Geotechnical Meeting, Icelandic Geotechnical Society, Reykjavik, pp. 587-596, https://www.ngm2016.com/uploads/2/1/7/9/21790806/064-057ngm_2016_-_numerical_models_on_anisotropy_of_rocks_kassa.pdf

Kim, D 2016, Study on the accuracy of rock surface roughness data using close range photogrammetry, PhD Thesis, Griffith University, Brisbane.

Leong, EC \& Rahardjo, H 2012, 'Two and three-dimensional slope stability reanalyses of bukit batok slope', Computers and Geotechnics, vol. 42, pp. 81-88.

Mohamad, AB, Zain, AM \& Bazin, NEN 2014, 'Cuckoo search algorithm for optimization problems - A literature review and its applications', Applied Artificial Intelligence, vol. 28, no. 5, pp. 419-448, https://doi.org/10.1080/08839514.2014.904599

Nian, TK, Huang, RQ, Wan, SS \& Chen, GQ 2012, 'Three-dimensional strength-reduction finite element analysis of slopes: geometric effects', Canadian Geotechnical Journal, vol. 49, issue 5, pp. 574-588.

Nunes, ALLS 2002 'A new method for determination of transverse isotropic orientation and the associated elastic parameters for intact rock', International Journal of Rock Mechanics and Mining Sciences, vol. 39, issue 2, pp. 257-273.

Özvan, A, Dinçer, I, Acar, A \& Özvan, B. 2014, 'The effects of discontinuity surface roughness on the shear strength of weathered granite joints', Bulletin of Engineering Geology and the Environment, https://doi.org/10.1007/s10064-013-0560-x

Riquelme, AJ, Abellán, A, Tomás, R \& Jaboyedoff, M 2014, 'A new approach for semi-automatic rock mass joints recognition from 3D point clouds', Computers and Geosciences, vol. 68, pp. 38-52, https://doi.org/10.1016/j.cageo.2014.03.014

Salvini, R, Mastrorocco, G, Seddaiu, M, Rossi, D \& Vanneschi, C 2017, 'The use of an unmanned aerial vehicle for fracture mapping within a marble Quarry (Carrara, Italy ): photogrammetry and discrete fracture network modelling', Geomatics, Natural Hazards and Risk, vol. 8, issue 1, pp, 34-52, http://dx.doi.org/10.1080/19475705.2016.1199053

Snow, DT 1969, 'Anisotropic permeability of fractured media', Water Resources Research, vol. 5, no. 6, pp, 1273-1289.

Westoby, MJ, Brasington, J, Glasser, NF, Hambrey, MH \& Reynolds, JM 2012, "Structure-from-motion' photogrammetry: a low-cost, effective tool for geoscience applications', Geomorphology, vol. 179, pp, 300-314, http://dx.doi.org/ 10.1016/j.geomorph.2012.08.021

$\mathrm{Wu}, \quad \mathrm{A}$ 2012, Locating General Failure Surfaces in Slope Analysis via Cuckoo Search, Rocscience, https://www.rocscience.com/help/slide2/pdf_files/theory/Cuckoo_Search.pdf 
